ledge places on them. The approach to testing and the associated counselling and support seem likely to be crucial factors.

Of equal concern are the wider aspects of a predictive test. Confidentiality of results will be essential, yet in some circumstances the result for one person will directly affect the risks for other family members. What will happen if there is disagreement within a family about testing? Will pressure be brought to bear on individuals at risk to be tested when faced with problems of insurance or employment? These are all real difficulties for families with Huntington's chorea at present, but they may be increased rather than diminished by the availability of predictive testing.

Several tasks require to be done urgently in the short time that remains before predictive testing is a reality. The most important are defining guidelines for preparation, counselling, and support for those undergoing testing and ensuring that any centre that undertakes testing is not only reliable in laboratory techniques but has the experience and capacity also to provide counselling and support. Accurate genetic records and diagnostic information on affected subjects are further prerequisites. Almost certainly the tests should be made available at first only in a few centres that are staffed and equipped to deal with a difficult, demanding, and probably disturbing undertaking for all concerned.

How should doctors react when approached by patients and relatives who learn of the existence of the new developments, and who may construe them as being an immediately available test, without knowledge of the limitations outlined here? The following suggestions may help until the picture becomes clearer.

Firstly, every effort should be made to take a blood sample for isolation of DNA from affected patients and elderly key relatives who may die soon, since without this information prediction for the younger generation may be impossible. Once DNA is isolated it is stable for many years. Secondly, diagnostic accuracy is now more essential than ever. Clearly, no predictive test for Huntington's chorea will be valid if the diagnosis is in fact a different brain disorder. A careful postmortem examination of the brain should be performed on all patients - and apparently healthy relatives at risk-when they die. Thirdly, relatives should be prepared in advance for. prediction, so that they can think about the implications thoroughly and not be panicked into being tested.

Lastly, those charitable bodies who are concerned with Huntington's chorea and the senior administrators responsible for the organisation and funding of genetic investigations need to give serious thought about how the challenge of predictive tests in this and other genetic disorders should be handled.

P S HARPER

Professor and Consultant in Medical Genetics,

Department of Medicine,

Welsh National School of Medicine,

Cardiff CF4 4XN

1 Hayden MR. Huntington's chorea. New York: Springer-Verlag, 1981

" Gusella JF, Wexler NS, Conneally PM, et al. A polymorphic DNA marker genetically linked to Huntington's disease. Nature $1983 ; 306: 234-8$.

3 Anonymous. Predictive tests in Huntington's chorea. [Editurial.] $\mathrm{Br} \mathrm{MedF}$ $1978 ; \mathrm{i}: 528-9$

'Themas S. Ethics of a predictive test for Huntington's chorea. Br Med 7 $1982 ; 284: 1383-5$.

Barette J, Marsden CD. Attitudes of families to some aspects of Huntington's chorea. Psychol Med 1979;9:327-36.

${ }^{6}$ Tyler A, Harper PS. Attitudes of subjects at risk and their relatives towards genetic counselling in Huntington's chorea. F Med Genet 1983;20: 179-88.

\section{The pathogenesis of cutaneous malignant melanoma}

The incidence of cutaneous malignant melanoma is rising in areas of the world for which good epidemiological data are available. These include Scandinavia, ${ }^{1}$ which has an incidence of 11 new cases per 100000 per year, Queensland ${ }^{2}$ at 32 per 100000 per year, and the southern states of North America, notably Arizona ${ }^{3}$ and New Mexico. ${ }^{4}$ The rate of increase is more rapid than for any other tumour. In Scandinavia the incidence is doubling every 10 years and in Queensland every 15. In New Mexico and Arizona the incidence has quadrupled in the past 10 years. Here the increase is confined to the "Anglo" population of north European descent. Negroes and those of Spanish or Mexican descent have no demonstrable increased incidence.

Within Britain available figures also suggest a rising incidence. In England and Wales in 1962-70 the rate was 1.38 per 100000 in men and 2.59 per 100000 a year in women. ${ }^{5}$ By $1977^{6}$ these figures had risen to 2.3 for men and 4.4 for women. In Scotland in 1979 the age adjusted incidence figures were 3.7 per 100000 for men and 6.2 per 100000 for women. ${ }^{7}$ Work done at the Oxford Cancer Registry ${ }^{8}$ has detected clear jumps in incidence two years after a particularly warm summer, suggesting that the latent period between sun induced induction or promotion and a detectable lesion may be relatively short by comparison with other tumours. These figures apply only to cutaneous malignant melanoma: available figures for ocular melanoma show no increasing incidence in any part of the world."

The epidemiological evidence suggests that this rapidly increasing incidence is related to greater exposure of white skin to strong natural sunlight. The association between exposure to sunlight and subsequent development of malignant melanoma is not, however, linear. The patient with a melanoma is not the man or woman who has spent a lifetime in an outdoor occupation and who has a high total lifetime dose of natural sunlight, predominantly in the ultraviolet light B range. This type of individual is, in fact, at increased risk of development of other skin cancers-either basal cell carcinoma or squamous cell carcinoma. ${ }^{10}$ By contrast, the patient with melanoma is two or three decades younger and is most often an indoor office worker of high socioeconomic state. ${ }^{11}$ Such profiles suggest that recreational exposure to the sun may play an important part in the aetiology of malignant melanoma, and a recent Scottish study has shown a correlation between severe sunburn and development of melanoma in the following five years, suggesting that short episodes of intense burning sunlight exposure are a risk factor. ${ }^{12}$ Similar evidence comes from a Scandinavian study which suggests that patients with melanoma do not tolerate ultraviolet light exposure well and burn and freckle easily. ${ }^{13}$

Recent work from Queensland has further highlighted the enigmas surrounding melanoma and sunlight. If the total amount of sun available and the incidence of melanoma were correlated in a direct linear fashion then there would be an inverse linear relation between incidence of the tumour and distance from the equator. In a careful analysis of the Queensland data Green and Siskind ${ }^{14}$ have shown that no such relation holds true for that part of the world. Queensland may be divided neatly into four distinct climatic zones: tropical coastal, subtropical coastal, tropical inland, and subtropical inland. The 
age standardised incidence rate for malignant melanoma of the nodular and superficial spreading types per 100000 of the population for 1979-80 was highest in the subtropical coastal area at $37 \cdot 2$, followed by the tropical coastal at $36 \cdot 1$. The subtropical inland figure was $23 \cdot 7$ and tropical inland $28 \cdot 8$. Thus the highest incidence is found in the coastal area around Brisbane, the major population centre in Queensland. Nevertheless, these observed differences in incidence are still entirely compatible with a role for exposure to ultraviolet light, in that measurement of ultraviolet light striking equipment on the ground is not the same as that striking patients' skin. The rural agricultural worker with limited access to sunbathing facilities is less likely to expose himself to excessive sun, or perhaps any sun, on areas other than face and hands than is his city dweller cousin, who has ready access to sunbathing facilities in lunch hours and at weekends and is tempted to make the most (or worst) of every burning ray.

The conclusion to be drawn from the Queensland research is that though measurement of hours of available daily ultraviolet light, and its intensity on the ground, is of considerable interest, it may not always give a true measure of patient cxposure. This may be done using light sensitive polysulphone monitors clipped to clothing. ${ }^{15}$ Use of these badges has already yielded interesting information about ambient ultraviolet light in different climatic conditions. ${ }^{16}$ Detailed documentation is also needed of lifestyles, sun exposure, tanning capacity, and other phenotypic variations in patients with melanoma and an appropriate number of controls.

The latest unknown factor to be added to the conundrum of ultraviolet light and melanoma is the use of sunbeds or artificial solaria. These machines emit light almost exclusively in the ultraviolet light $\mathrm{A}(320-360 \mathrm{~nm})$ range. Ultraviolet light A alone has been considered non-carcinogenic, but recent studies on animals suggest that ultraviolet light A may be able to accelerate or potentiate the well recognised carcinogenic capacity of ultraviolet light $\mathrm{B}$ in the development of nonmelanoma skin cancer. ${ }^{17}$ Retsas ${ }^{18}$ has recorded that nine of his patients with melanoma had used sunbeds regularly and two of our Glasgow patients give a similar history. More data and appropriate controls are needed to place these figures in proper perspective.

The current lack of a good animal model for malignant melanoma makes for difficulties in testing hypotheses about the parts played by constant and intermittent exposure to ultraviolet light on either normal skin or on melanocytic naevi. A further problem, outside the scope of this leading article is the recently recognised change in the immune system in animals after exposure to ultraviolet light $\mathrm{B}^{19}$ and in man after exposure to ultraviolet rays from commercial solaria. ${ }^{20}$ Surveys of immunosuppressed patients with renal transplants have found a higher than expected incidence of non-melanoma skin cancer, suggesting that for certain tumour types the Burnett hypothesis of immune surveillance remains valid. ${ }^{21}$ Data on melanoma in patients with transplants are limited, but here again the incidence appears to be higher than expected. ${ }^{22}$ The possible interactions between ultraviolet light and hormonal state or pre-existing melanocytic naevi are outside the scope of this article.

At present, therefore, the exact sequence of events from initiation of the tumour to clinical expression of malignant melanoma is not clear. Environmental factors appear to play a very much greater part than heredity, implying that with greater understanding of the effects of ultraviolet light on both the cutaneous surface and possibly the immune system a substantial proportion of all cases of malignant melanoma might be prevented. Until this information is available the family doctor's most important contribution to management of malignant melanoma is recognition of the lesion in its very early stages and prompt referral of the patient for confirmation of the diagnosis and appropriate treatment. Caught in time, malignant melanoma is curable.

RONA M MACKIE

Professor of Dermatology,

University of Glasgow,

Glasgow G11 6NU

1 Magnus K. Incidence of malignant melanoma of the skin in Norway 1955-1970. Variations in time and space and solar radiation. Cancer 1973; $32: 1275-86$

Green A. Incidence and reporting of cutaneous melanoma in Queensland. Australas $\mathcal{F}$ Dermatol $1982 ; 23: 105-9$.

Schreiber MM, Bozzo PD, Moon TE. Malignant melanoma in Southern Arizona. Increasing incidence and sunlight as an etiologic factor. Arch Dermatol 1981;117:6.

4 Pathak DR, Samet JM, Howard CA, Key CR. Malignan melanoma of the skin in New Mexico 1969-1977. Cancer 1982;50:1440-60.

5 Office of Population Censuses and Surveys. Registrar General's statistical review of England and $W$ ales 1968-1970. Supplement in cancer. London: HMSO, 1975.

' Office of Population Censuses and Surveys. Registrar General's statistical review of England and Wales 1979. Supplement in cancer. London: HMSO, 1977.

Mackie RM, Hunter JAA. Cutaneous malignant melanoma in Scotland. Br F Cancer 1982;46:75-80.

Swerdlow AJ. Incidence of malignant melanoma of the skin in England and Wales and its relationship to sunshine. Br Med f 1979;ii:1324-7.

'Lee JAH. Melanoma and exposure to sunlight. Epidemiol Rev 1982;4: 110-36.

10 Gellin GA, Kopf AW, Garfinkel L. Malignant melanoma. A controlled study of possibly associated factors. Arch Dermatol 1969;99:43-8.

11 Lee JAH, Strickland D. Malignant melanoma: social status and outdoor work. Br f Cancer 1980;41:757-63.

12 MacKie RM, Aitchison TC. Severe sunburn and subsequent risk of primary cutaneous malignant melanoma in Scotland. Br f Cancer 1982; $46: 955-60$.

${ }^{13}$ Klepp O, Magnus K. Some environmental and bodily characteristics of melanoma patients. A case-control study. Int f Cancer 1979;23:482-6.

14 Green A, Siskind V. Geographical distribution of cutaneous melanoma in Queensland. Med F Aust 1983;i:407-10.

${ }^{15}$ Moseley $\mathrm{H}$, Davidson M, MacKie RM. Measurement of daylight UVA in Glasgow. Phys Med Biol 1983;5:589-97.

${ }^{16}$ Moseley H, Diffey BL, Marks JM, MacKie RM. Personal solar UV-A doses received by patients undergoing oral psoralen photochemotherapy for psoriasis. Br 7 Dermatol 1981;105:573-7.

17 Staberg B, Wulf HC, Poulsen T, Klemp P, Brodthagen H. Carcinogenic effect of sequential artificial sunlight and UV-A irradiation in hairless mice. Consequences for solarium therapy. Arch Dermatol 1983;119: 641-3.

${ }^{1}$ Retsas S. Sunbeds and melanoma. Br Med f 1983;286:892.

19 Kripke ML, Fisher MS. Immunological parameters of ultraviolet carcinogenesis. $\mathcal{F}$ Natl Cancer Inst 1976;57:211-5.

20) Hersey P, Bradley M, Hasic E, Haran G, Edwards A, McCarthy WH. Immunological effects of solarium exposure. Lancet 1983;i:545-8.

${ }^{21}$ Hoxtel EO, Mandel JS, Murray SS, Schuman LM, Goltz RW. Incidence of skin carcinoma after renal transplantation. Arch Dermatol 1977;113: 436-8.

2.2 Greene $\mathrm{MH}$, Young TI, Clark WH Jr. Malignant melanoma in renal transplant recipients. Lancet $1981 ; \mathrm{i}: 1196-8$.

\section{Who should be an author}

Papers with many authors are becoming more common. In the early 'forties papers published in the New England fournal of Medicine averaged just under two authors; in 1978 the figure was just under five. ${ }^{1}$ This increase has led editors and others to question how much each of these many authors may actually have contributed to the paper-and how far each would be willing to take responsibility for it, ${ }^{2-4}$ for editorial queries about the manuscript commonly elicit mumbled excuses about 